\title{
A novel GLA mutation in a Korean boy with an early cardiac manifestation of Fabry disease
}

\author{
Soonhak Kwon', Jin-Sung Park², Jae Hun Jung', Su Kyeong Hwang', Yeo Hyang Kim¹, and Yun Jeong Lee, ${ }^{1, *}$ \\ 'Department of Pediatrics, Kyungpook National University Hospital, School of Medicine, Kyungpook National University, Daegu, Korea \\ 2Department of Neurology, Kyungpook National University Hospital, School of Medicine, Kyungpook National University, Daegu, Korea
}

Fabry disease (FD) is a rare X-linked lysosomal storage disorder caused by the deficiency of $\alpha$-galactosidase A. Patients with classical FD present acroparesthesia, hypohidrosis, cornea verticillata, disseminated angiokeratoma, and microalbuminuria in childhood, and develop life-threatening renal, cardiac, and cerebrovascular complications typically after the fourth decade of life. To date, more than 700 mutations responsible for FD have been identified in the human GLA gene. Herein, we report a novel GLA mutation, c.1117_1141del25 (p.Gly373Profs*10), identified in an 11-year-old Korean boy with FD presenting early cardiac and neurologic manifestation and in other affected family members. The boy had acroparesthesia, hypohidrosis, cornea verticillata, and left ventricular hypertrophy. His mother and sister also had acroparesthesia. Two males on the mother's side had similar pain and died of unknown causes. The plasma $\alpha$-galactosidase A activity $(4.1 \mathrm{nmol} / \mathrm{hr} / \mathrm{mg}$ protein) of the patient was markedly lower than the mean value of the controls. The plasma level of globotriaosylsphingosine was elevated in the patient and all the carriers. We concluded the novel GLA mutation c.1117_1141del25 is a pathogenic mutation for FD, probably related to the early cardiac manifestation of FD.

Key words: Fabry disease, Lysosomal storage diseases, $\alpha$-Galactosidase.

\section{Introduction}

Fabry disease (FD; OMIM: 301500) is an X-linked lysosomal storage disorder caused by mutations in the GLA gene, which encodes the lysosomal hydrolase $\alpha$-galactosidase A. The deficiency of this enzyme causes the progressive accumulation of globotriaosylceramide (Gb3) and globotriaosylsphingosine (lysoGb3) in the lysosomes of various cells, subsequently leading to significant cellular dysfunction and organ damage. Patients with classical FD often present with characteristic features such as acroparesthesia, hypohidrosis, cornea verticillata, disseminated angiokeratoma, and microalbuminuria during early childhood and adolescence. In later stages, they may develop progressive kidney disease, hypertrophic cardiomyopathy, and cerebrovascular disease, which eventually lead to significant morbidity and mortality [1-4]. In contrast, patients with non-classical FD tend to present mild symptoms, occasionally limited to heart or kidney conditions [5]. Therefore, the diagnosis of FD is often delayed or missed completely because of the wide variety of symptoms [6]. The average delay from the onset of symptoms to diagnosis is more than a decade [6]. The introduction of enzyme replacement therapy (ERT) may make it possible to halt or even reverse

Received: 8 April 2018, Revised: 15 May 2018, Accepted: 16 May 2018, Published: 30 June 2018

*Corresponding author: Yun Jeong Lee, M.D. (iD http://orcid.org/0000-0003-3472-5336

Department of Pediatrics, Kyungpook National University Hospital, School of Medicine, Kyungpook National University, 130 Dongdeok-ro, Jung-gu, Daegu 41944, Korea.

Tel: +82-53-200-5704, Fax: +82-53-425-6683, E-mail: oilily1103@hanmail.net

Conflict of interest: The authors declare that they do not have any conflicts of interest.

(c) This is an open-access article distributed under the terms of the Creative Commons Attribution Non-Commercial License (http://creativecommons.org/licenses/by-nc/4.0/) which permits unrestricted non-commercial use, distribution, and reproduction in any medium, provided the original work is properly cited.

(c) Copyright 2018 by the Korean Society of Medical Genetics and Genomics 
the progress of symptoms before irreversible organ damage occurs [7]. Thus, early diagnosis of FD before the development of organ dysfunction is very important in improving a patient's outcome and quality of life.

Herein, we report the identification of a novel GLA mutation, c.1117_1141del25, in a Korean family with FD experiencing predominantly cardiac and neurologic symptoms.

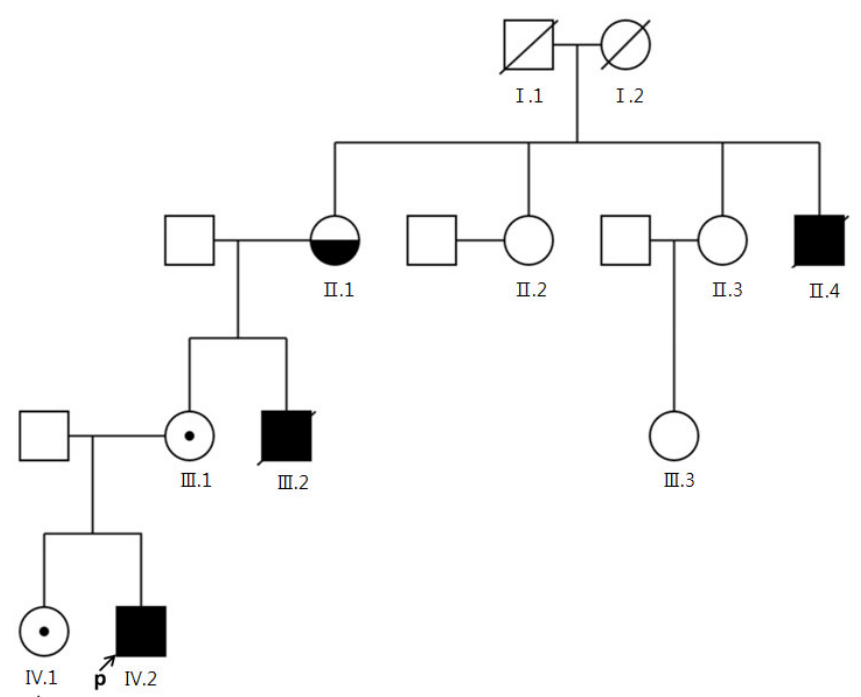

Fig. 1. Pedigree of the family harboring the c.1117_1141del25 GLA gene mutation. The squares and circles indicate males and females, respectively. The arrow indicates the proband. The shaded squares indicate affected males. The circles with dots indicate heterozygous females. The black and white circle indicates the suspected female carrier. A slash through a circle or a square indicates a deceased individual.

\section{Case}

An 11-year-old boy was referred to our pediatric neurology clinic because of chronic pain with acute exacerbation on both fingertips and toes and fever for 2 days. He had symmetric burning or stabbing pain in his distal extremities, which waxed and waned over the past 3 years. His pain was aggravated by heat and cold exposure or physical activities. He also presented with anhidrosis and fatigue. His perinatal history was uneventful. His mother's uncle (II.4) and his uncle (III.2) experienced similar pain in their childhood and adolescence and died of unknown causes in their mid-twenties (Fig. 1). His grandmother (II.1) also had similar pain and mitral valve replacement in her fifties, and has had repeated episodes of stroke thereafter. His mother (III.1) and sister (IV.1) have similar, but mild pain. On physical examination, no skin lesion such as angiokeratoma was seen, but cornea verticillata was observed in an ophthalmologic examination. His neurologic examination findings were normal except for heat or cold intolerance on his hands and feet. The findings of nerve conduction studies and electromyography were unremarkable, but autonomic sweating response was absent on the quantitative sudomotor axon reflex test. His echocardiogram showed an increased thickness of the interventricular septum $(11.1 \mathrm{~mm}$; Zscore, 2.65) and left ventricular (LV) posterior wall (8.8 $\mathrm{mm} ; \mathrm{Z}-$ score, 2.19), suggestive of left ventricular hypertrophy (LVH) in the M-mode measurements (LV mass index, $120 \mathrm{~g} / \mathrm{m}^{2}$ ) (Fig. 2A). An electrocardiogram revealed a sinus rhythm with signs of $L \mathrm{VH}_{1}$ tall $\mathrm{R}$-waves in the $\mathrm{V}_{5}-\mathrm{V}_{6}$ leads, and deep $\mathrm{S}$-waves in the $\mathrm{V}_{2}$ lead (Fig. 2B).

On the basis of the clinical and laboratory findings, along with

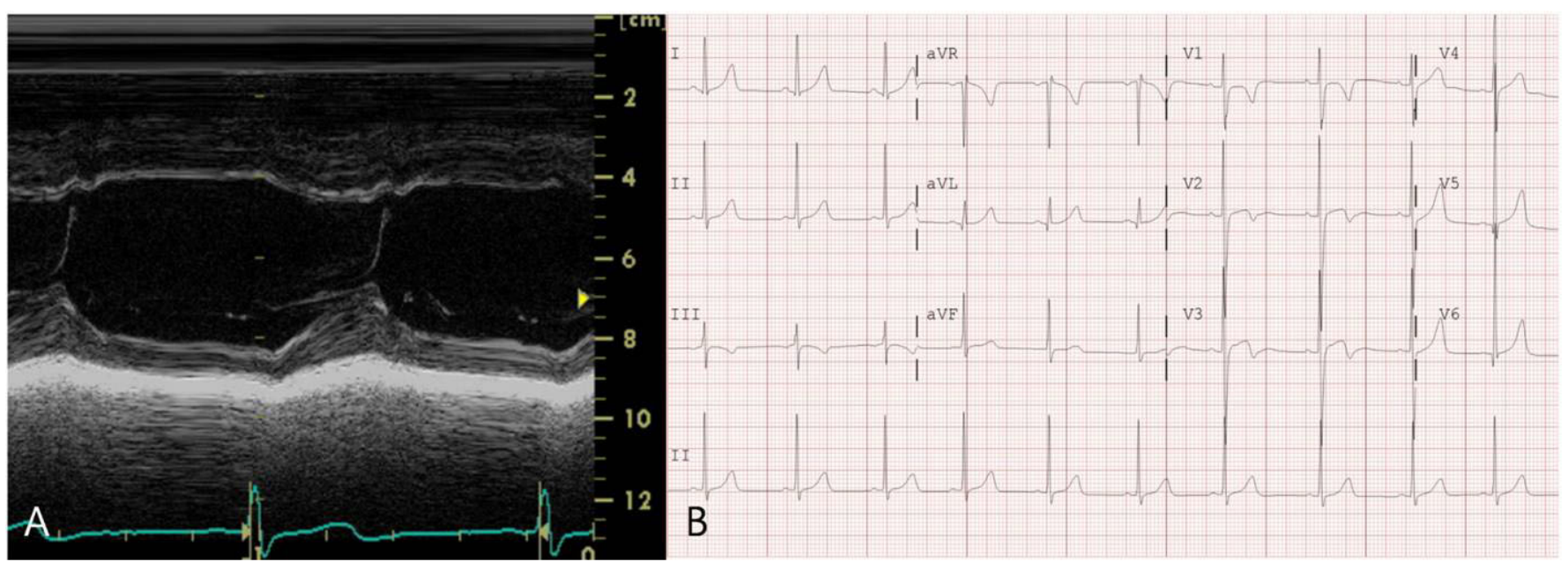

Fig. 2. (A) Echocardiogram of the proband shows the presence of left ventricular hypertrophy (LVH). (B) The electrocardiogram of the proband reveals a sinus rhythm with signs of $L V H$, tall R-waves in the $V_{5}-V_{6}$ leads, and deep S-waves in the $V_{2}$ lead. 
the family history, we suspected the patient had FD. Accordingly, we tested $\alpha$-galactosidase $A$ enzyme activities and performed DNA sequencing of the GLA gene using serum samples collected from the patient, his mother, and sister. The patient's GLA enzyme activity in blood leukocytes was markedly lower than the mean value of the controls $(4.1 \mathrm{nmol} / \mathrm{hr} / \mathrm{mg}$ protein vs. 72.9 $\mathrm{nmol} / \mathrm{hr} / \mathrm{mg}$ protein). The cutoff value that indicates below-normal $\alpha$-galactosidase A enzyme activity in plasma is $35 \mathrm{nmol} / \mathrm{hr} /$ mg protein. $\alpha$-Galactosidase A enzyme activities in his mother and sister were 50.1 and $54.3 \mathrm{nmol} / \mathrm{hr} / \mathrm{mg}$ protein, respectively, which were within the normal limit (normal controls, $103 \mathrm{nmol} /$ $\mathrm{hr} / \mathrm{mg}$ protein). DNA sequencing of the $G L A$ gene revealed that the patient, his mother, and sister carried a novel mutation, c.1117_1141del25 (p.Gly373Profs*10), in exon 7 (Fig. 3). The levels of plasma lyso-Gb3 were increased in all affected family members, especially in the male patient (Table 1).

After identifying the GLA mutation, all affected female carriers revisited our clinics for detailed assessments including car-

A.

Wild-type allele

\begin{tabular}{lllllllllllllllll}
370 & 371 & 372 & 373 & 374 & 375 & 376 & 377 & 378 & 379 & 380 & 381 & 382 & 383 & 384 & 385 & 386 \\
Ala & Ser & Leu & Gly & Lys & Gly & Val & Ala & Cys & Asn & Pro & Ala & Cys & Phe & Ile & Thr & Gln \\
\hline
\end{tabular}

\section{Wild-type allele}
$\overline{\text { GCT }} \overline{\text { TCC }} \overline{\text { CTG }} \overline{\text { GGT }} \overline{\text { AAA }} \overline{\overline{G G A}} \overline{\overline{G T G}} \overline{\text { GCC TGT AAT }} \overline{\overline{C C T}} \overline{\overline{G C C}} \overline{\mathrm{TGC}} \overline{\text { TTC }} \overline{\overline{\text { ATC }}} \overline{\overline{\text { ACA }}} \overline{\mathrm{CAG}}$ 25-base deletion (c.1117_1141del25, p.Gly373Profs*10)
Mutant allele
$\frac{\text { Ala }}{\text { GCT }} \frac{\text { Ser }}{\text { TCC }} \frac{\text { Leu }}{\text { CTG }} \frac{\text { Pro }}{\text { CCT }} \frac{\text { Ala }}{\text { GCT }} \frac{\text { Ser }}{\text { TCA }} \frac{\text { Ser }}{\text { TCA }} \frac{\text { His }}{\text { CAC }} \frac{\text { Ser }}{\text { AGC }} \frac{\text { Ser }}{\text { TCC }} \frac{\text { Ser }}{\text { TCC }} \frac{\text { Leu }}{\text { CTG }} \frac{*}{\text { TGA }}$
Wile type DNA sequence

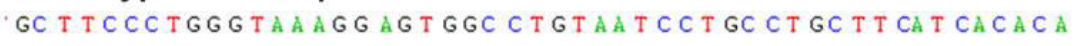

B.

Father

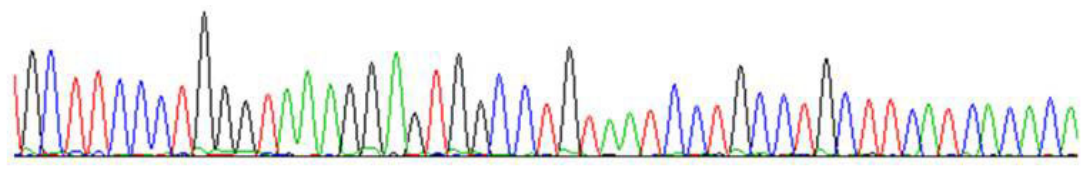

Heterozygous mutant DNA sequence

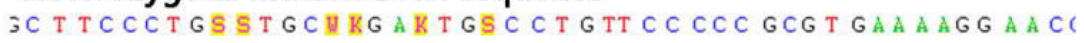

III.1

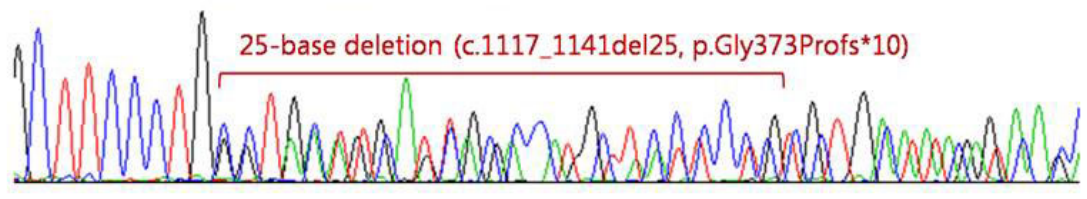

Heterozygous mutant DNA sequence

GC T TCCCT GS S T GC B RG A R T GSCCA G C T C C CCC GCG T GA A A AG A A A S

IV.1

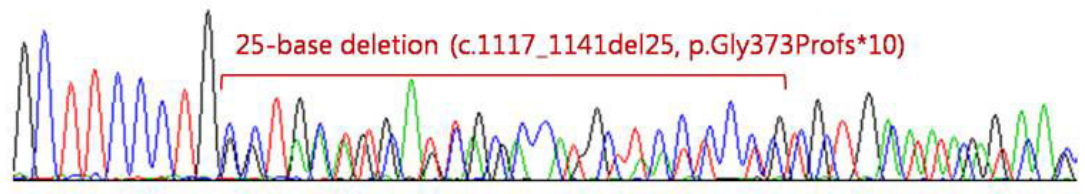

Hemizygous mutant DNA sequence

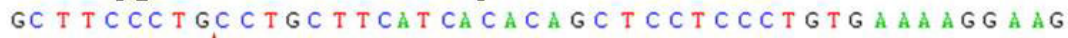

$\Lambda_{25-b a s e}$ deletion

IV.2

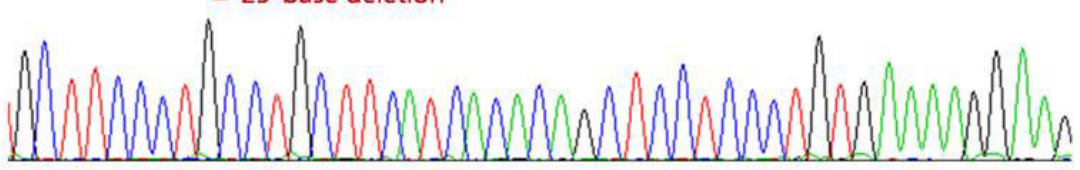

Fig. 3. (A) The DNA and corresponding amino acid sequences of the wild-type and mutant GLA alleles are shown. The 25-base deletion at nucleotide 1117-1141 shifts the frame, leading to premature termination at amino acid 382 in exon 7. (B) Representative chromatograms of polymerase chain reaction, fragments showing the presence of the 25-base deletion in the index patient (IV.2) and two female carriers (III.1 and IV.1), but not in the unaffected father. 
Table 1. Clinical features of the affected family members described in this case report

\begin{tabular}{|c|c|c|c|c|c|c|c|c|}
\hline Patient & $\begin{array}{l}\text { Sex/ } \\
\text { age (yr) }\end{array}$ & Nervous system & $\begin{array}{l}\text { Cardiovascular } \\
\text { system }\end{array}$ & Nephrology system & $\begin{array}{c}\text { Other } \\
\text { symptoms }\end{array}$ & $\begin{array}{l}\text { GLA enzyme activity } \\
\text { (nmol/hr/mg protein) }^{\mathrm{a}}\end{array}$ & $\begin{array}{l}\text { Gb3 level } \\
(\mu \mathrm{g} / \mathrm{mL})^{b}\end{array}$ & $\begin{array}{l}\text { Lyso- } \\
\text { Gb3 level } \\
(\mathrm{ng} / \mathrm{mL})^{c}\end{array}$ \\
\hline IV.2 & $M / 11$ & $\begin{array}{l}\text { Neuropathic } \\
\text { pain, anhidro- } \\
\text { sis }\end{array}$ & $\begin{array}{l}\text { Left ventricular hypertrophy } \\
\left.\text { (LV mass index: } 120 \mathrm{~g} / \mathrm{m}^{2}\right)\end{array}$ & $\begin{array}{l}\text { eGFR } 110 \mathrm{~mL} / \mathrm{min} / 1.73 \mathrm{~m}^{2} \\
\text { Microalbuminuria }(-) \\
\text { Biopsy: zebra body in podocyte } \\
\text { and epithelial cell }\end{array}$ & $\begin{array}{l}\text { Cornea } \\
\text { verticillata }\end{array}$ & 4.1 & 23.6 & 95.4 \\
\hline IV.1 & $F / 13$ & Neuropathic pain & Mitral valve prolapse & $\begin{array}{l}\text { eGFR } 145 \mathrm{~mL} / \mathrm{min} / 1.73 \mathrm{~m}^{2} \\
\text { Microalbuminuria }(-)\end{array}$ & $\begin{array}{l}\text { Cornea } \\
\text { verticillata }\end{array}$ & 54.3 & 7.5 & 1.86 \\
\hline |ll.1 & $F / 45$ & $\begin{array}{l}\text { Neuropathic } \\
\text { pain, hypohi- } \\
\text { drosis }\end{array}$ & Unremarkable & $\begin{array}{l}\text { eGFR } 97 \mathrm{~mL} / \mathrm{min} / 1.73 \mathrm{~m}^{2} \\
\text { Microalbuminuria }(+) \\
\text { (48 mg/g creatinine) }\end{array}$ & $\begin{array}{l}\text { Cornea } \\
\text { verticillata }\end{array}$ & 50.1 & 7.7 & 4.44 \\
\hline
\end{tabular}

GLA, $\alpha$-galactosidase A; Gb3, globotriaosylceramide; lyso-Gb3, globotriaosylsphingosine; LV, left ventricular; eGFR, estimated glomerular filtration rate. Normal range: ${ }^{a}>35.0 \mathrm{nmol} / \mathrm{hr} / \mathrm{mg}$ protein; $3.9-9.9 \mu \mathrm{g} / \mathrm{mL} ;{ }^{\circ} \leq 1.74 \mathrm{ng} / \mathrm{mL}$.

diologic, nephrologic, dermatologic, ophthalmologic, and neurologic assessments, as well as auditory function. Both of them showed normal electrocardiogram result without sign of cardiac rhythm disturbance. On echocardiogram, his sister showed mitral valve prolapse. His mother had mild microalbuminuria (48 $\mathrm{mg} / \mathrm{g}$ creatinine). Both of them showed cornea verticillata in their ophthalmologic examinations.

The patient's urine test showed no significant microalbuminuria (7.8 $\mu \mathrm{g} / \mathrm{min})$, but a renal biopsy was performed to evaluate the presence of organ involvement before ERT. In the light microscopy, the glomeruli are diffusely enlarged. No glomerular sclerosis, crescent formation, chronic tubulointerstitial changes were observed. Electron microscopy revealed diffuse deposits of zebra bodies in podocytes and tubular epithelial cells with diffuse thickening of glomerular basement membrane and focal foot processes effacement (Fig. 4). The patient has started ERT with agalsidase beta $1.0 \mathrm{mg} / \mathrm{kg}$ every 2 weeks and supportive pain management, while his mother and sister have been examined the symptoms and signs of Fabry's disease on a regular basis without starting ERT.

\section{Discussion}

We identified a novel GLA mutation (c.1117_1141del25) in a Korean family with FD. The presence of $\mathrm{LVH}$, chronic neuropathic pain, cornea verticillata, and a strong family history raised the suspicion of FD and led to an excellent diagnosis in the proband.

FD is a devastating, progressive metabolic disorder caused by a defect in $\alpha$-galactosidase A activity, and it has an incidence rate of 1 in 40,000 to 118,000 live births for males. The $\alpha$-galactosidase A enzyme defect leads to the systemic accumulation of Gb3 and lyso-Gb3 inside the lysosomes of vascular endothelial cells, renal epithelial cells, myocardial cells, and neu-

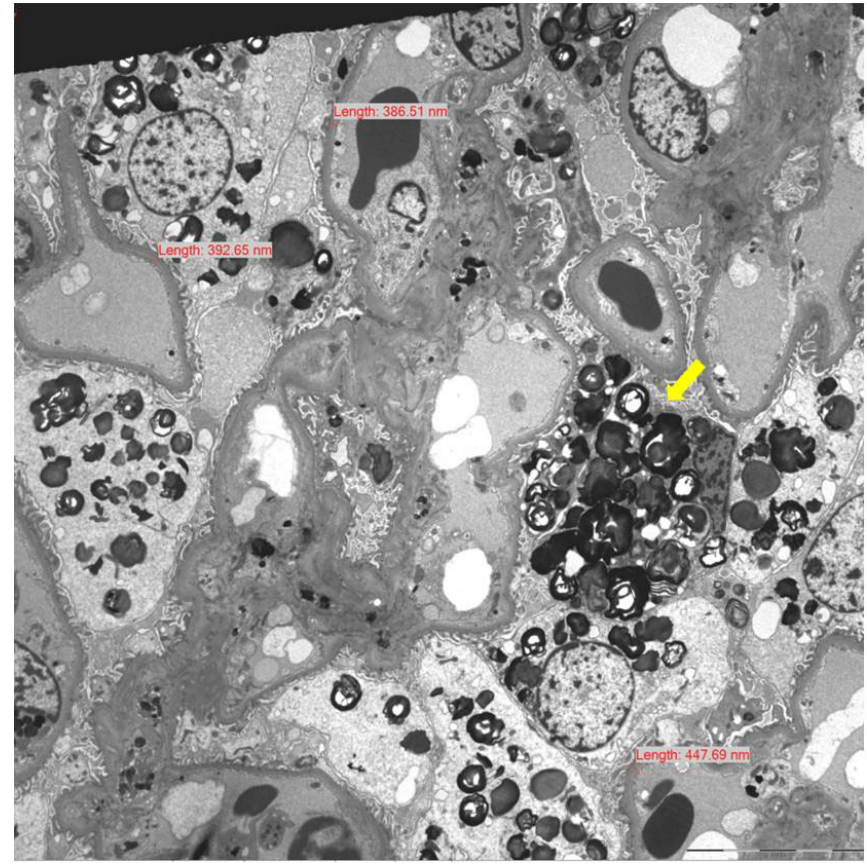

Fig. 4. Electron microsopy of renal biopsy showing multi-lamellated myelin figures, so-called zebra bodies in patient's podocyte and epithelial cell (arrow). Also, diffuse thickening of glomerular basement membrane and focal foot processes effacement were observed $(\times 5,000)$.

rons of the dorsal root ganglia and autonomic nervous system, resulting in a variety of multi-organ dysfunctions [8]. In classical FD, cardiac manifestation such as LVH arises typically during the fourth to seventh decades of life and at a later age in females than in males [9]. The proband in our report presented LVH at an earlier age than that seen in classical FD [10]. This suggests the novel GLA mutation (c.1117_1141del25) may be related to the early onset and severe cardiac phenotype of FD.

As in the present patient, pain is one of the earliest and predominant clinical symptoms of FD, affecting $60-70 \%$ of male 
and $40-60 \%$ of female patients [3,4]. Neuropathic pain and heat and cold intolerance often begin at an average age of 6 to 8 years in males and, generally, a few years later in females than in males [6,11]. Typically, pain in FD manifests as episodes of burning, stabbing, or shooting pain that begins in the distal extremities with various triggering factors such as physical exercise, thermal stimuli, and fever [4]. Therefore, unexplained neuropathic pain in pediatric patients should alert the physician to the possibility of FD.

As FD is an X-linked genetic disorder, in the past, females were generally considered symptomatic carriers. Nevertheless, in recent years, it is widely accepted that heterozygous female carriers could develop mild to severe clinical manifestations of FD $[6,12]$. Females with FD can show wide variations in $\alpha$-galactosidase A activity, ranging from severely deficient to normal levels possibly depending on random $\mathrm{X}$-chromosome inactivation $[13,14]$. Although the progression of FD is slower and variable in female carriers, regular monitoring for signs and symptoms of FD is needed to recognize candidates for ERT. Plasma lyso-Gb3 level appears a useful biomarker for therapeutic evaluation and monitoring, particularly in females with normal and/or borderline $\alpha$-galactosidase A activity $[15,16]$. Consistent with this findings, the two affected heterozygous females in our report, presenting mild symptom of $F D$, had normal $\alpha$-galactosidase A activities, normal Gb3 level, and increased serum lyso-Gb3 levels.

Recently, more than 700 mutations in the GLA gene have been identified as pathogenic variants of FD. However, the diagnosis of FD is often difficult in several subjects because they have a $G L A$ genetic variant of unknown significance. According to the current recommendations of the American College of Medical Genetics and Genomics and the Association for Molecular Pathology, multiple lines of evidence could be used to characterize the novel GLA mutation (c.1117_1141del25) as "pathogenic" for FD [17]. First, this mutation causes a frameshift leading to protein truncation by introducing a premature stop codon at position 382, which is assumed to disrupt GLA gene function. Second, the observation of the markedly decreased GLA enzyme level in the affected male carrier and the increased lyso-Gb3 levels in all the mutation carriers provides evidence for a damaging effect on the GLA enzyme. Third, the mutation is absent among the controls in the Exome Sequencing Project, 1000 Genomes Project, or Exome Aggregation Consortium. Furthermore, a different amino acid change occurring at p.Gly373 (p.Gly373Ser, pGly373Arg, or p.Gly373Asp) has previously been determined to be pathogenic for FD. Lastly, this novel GLA mutation was ob- served to segregate with the phenotype suggestive of FD in all affected family members.

In summary, we identified a novel GLA mutation (c.1117_ 1141 del25) in a Korean family with FD. Particularly, the cardiac manifestation was detected early on in this patient, and this phenotype may be related to the novel GLA mutation. Our report may help accumulate knowledge about the correlation between the genotype and phenotype in FD.

\section{Acknowledgements}

The authors thank Sanofi Genzyme Korea for their scientific support. We especially appreciate the assistance provided by Ji Won Park and Soo Min Han. The enzyme assay and genetic test were supported by Sanofi Genzyme Korea's Rare Disease Diagnostic Support Program.

\section{References}

1. Desnick RJ. Enzyme replacement therapy for Fabry disease: lessons from two alpha-galactosidase A orphan products and one FDA approval. Expert Opin Biol Ther 2004;4:1167-76.

2. MacDermot KD, Holmes $A$, Miners AH. Anderson-Fabry disease: clinical manifestations and impact of disease in a cohort of 98 hemizygous males. J Med Genet 2001;38:750-60.

3. Eng CM, Fletcher J, Wilcox WR, Waldek S, Scott CR, Sillence DO, et al. Fabry disease: baseline medical characteristics of a cohort of 1765 males and females in the Fabry Registry. J Inherit Metab Dis 2007;30:184-92.

4. Politei JM, Bouhassira D, Germain DP, Goizet C, Guerrero-Sola A, Hilz $\mathrm{MJ}$, et al. Pain in Fabry disease: practical recommendations for diagnosis and treatment. CNS Neurosci Ther 2016;22:568-76.

5. Cammarata G, Fatuzzo P, Rodolico MS, Colomba P, Sicurella L, lemolo F, et al. High variability of Fabry disease manifestations in an extended Italian family. Biomed Res Int 2015;2015:504784.

6. Mehta A, Ricci R, Widmer U, Dehout F, Garcia de Lorenzo A, Kamp-

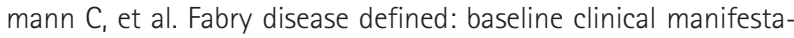
tions of 366 patients in the Fabry Outcome Survey. Eur J Clin Invest 2004;34:236-42.

7. Choi JH, Cho YM, Suh KS, Yoon HR, Kim GH, Kim SS, et al. Short-term efficacy of enzyme replacement therapy in Korean patients with Fabry disease. J Korean Med Sci 2008;23:243-50.

8. Desnick RJ, Brady R, Barranger J, Collins AJ, Germain DP, Goldman $M$, et al. Fabry disease, an under-recognized multisystemic disorder: expert recommendations for diagnosis, management, and enzyme replacement therapy. Ann Intern Med 2003;138:338-46. 
9. Kampmann $C$, Linhart A, Baehner F, Palecek T, Wiethoff CM, Miebach $E_{1}$ et al. Onset and progression of the Anderson-Fabry disease related cardiomyopathy. Int J Cardiol 2008;130:367-73.

10. Wilson HC, Hopkin RJ, Madueme PC, Czosek RJ, Bailey LA, Taylor $M D$, et al. Arrhythmia and clinical cardiac findings in children with Anderson-Fabry disease. Am J Cardiol 2017;120:251-5.

11. Hopkin RJ, Bissler J, Banikazemi M, Clarke L, Eng CM, Germain DP, et al. Characterization of Fabry disease in 352 pediatric patients in the Fabry Registry. Pediatr Res 2008;64:550-5.

12. MacDermot KD, Holmes A, Miners AH. Anderson-Fabry disease: clinical manifestations and impact of disease in a cohort of 60 obligate carrier females. J Med Genet 2001;38:769-75.

13. Sharp A, Robinson D, Jacobs P. Age- and tissue-specific variation of $X$ chromosome inactivation ratios in normal women. Hum Genet 2000;107:343-9.

14. Redonnet-Vernhet I, Ploos van Amstel JK, Jansen RP, Wevers RA,
Salvayre $\mathrm{R}$, Levade T. Uneven $\mathrm{X}$ inactivation in a female monozygotic twin pair with Fabry disease and discordant expression of a novel mutation in the alpha-galactosidase A gene. J Med Genet 1996:33:682-8.

15. Togawa T, Kodama T, Suzuki T, Sugawara K, Tsukimura T, Ohashi T, et al. Plasma globotriaosylsphingosine as a biomarker of Fabry disease. Mol Genet Metab 2010;100:257-61.

16. Nowak A, Mechtler TP, Desnick RJ, Kasper DC. Plasma LysoGb3: a useful biomarker for the diagnosis and treatment of Fabry disease heterozygotes. Mol Genet Metab 2017;120:57-61.

17. Richards S, Aziz N, Bale S, Bick D, Das S, Gastier-Foster J, et al. Standards and guidelines for the interpretation of sequence variants: a joint consensus recommendation of the American College of Medical Genetics and Genomics and the Association for Molecular Pathology. Genet Med 2015;17:405-24. 